\title{
SCIENTIFIC REP RTS \\ Author Correction: The relationship between plasma ferritin levels and body mass index among adolescents
}

\author{
Khulood K. Shattnawi ${ }^{1}$, Mahmoud A. Alomari ${ }^{2,3}$, Nihaya Al-Sheyab ${ }^{1}$ \& \\ Ayman Bani Salameh ${ }^{4}$
}

Correction to: Scientific Reports https://doi.org/10.1038/s41598-018-33534-4, published online 17 October 2018

The original version of this Article contained errors. The author Mahmoud A. Alomari was incorrectly listed as Mahmoud Alomari. As a result, the Author Contributions statement now reads:

"K.K.Sh., M.A.A., N.A. \& A.B. contributed to the acquisition, analysis and interpretation of data. All authors drafted the article and approved the final version to be published."

In addition, there were errors in the affiliation list, where Affiliation 1 was duplicated as Affiliation 3 and an additional affiliation for Mahmoud A. Alomari, 'Qatar University, Division of Physical Education, Department of Educational Sciences, Doha, Qatar' was omitted.

These errors have been corrected in the PDF and HTML versions of this Article.

(i) Open Access This article is licensed under a Creative Commons Attribution 4.0 International License, which permits use, sharing, adaptation, distribution and reproduction in any medium or format, as long as you give appropriate credit to the original author(s) and the source, provide a link to the Creative Commons license, and indicate if changes were made. The images or other third party material in this article are included in the article's Creative Commons license, unless indicated otherwise in a credit line to the material. If material is not included in the article's Creative Commons license and your intended use is not permitted by statutory regulation or exceeds the permitted use, you will need to obtain permission directly from the copyright holder. To view a copy of this license, visit http://creativecommons.org/licenses/by/4.0/.

(C) The Author(s) 2019

\footnotetext{
${ }^{1}$ Jordan University of Science and Technology, Maternal \& Child Health Nursing Department, Irbid, 22110, Jordan. 2Jordan University of Science and Technology, Division of Physical Therapy, Department of Rehabilitation Sciences, Irbid, 22110, Jordan. ${ }^{3}$ Qatar University, Division of Physical Education, Department of Educational Sciences, Doha, Qatar. ${ }^{4}$ Al-Zaytoonah University of Jordan, Faculty of Nursing, Amman, 11733, Jordan. Khulood K. Shattnawi, Mahmoud A. Alomari, Nihaya Al-Sheyab and Ayman Bani Salameh contributed equally. Correspondence and requests for materials should be addressed to K.K.S. (email: khuloods@just.edu.jo)
} 